\title{
The First Modified Delphi Consensus Statement for Resuming Bariatric and Metabolic Surgery in the COVID-19 Times
}

\author{
Sjaak Pouwels ${ }^{1} \cdot$ Islam Omar ${ }^{2} \cdot$ Sandeep Aggarwal ${ }^{3} \cdot$ Ali Aminian $^{4} \cdot$ Luigi Angrisani $^{5} \cdot$ Jose María Balibrea $^{6}$. \\ Mohit Bhandari $^{7}$. L. Ulas Biter ${ }^{8}$ - Robin P. Blackstone ${ }^{9}$. Miguel A. Carbajo ${ }^{10}$. Catalin A. Copaescu ${ }^{11}$. \\ Jerome Dargent ${ }^{12}$. Mohamed Hayssam Elfawal ${ }^{13}$ • Mathias A. Fobi ${ }^{7}$. Jan-Willem Greve ${ }^{14}$. Eric J. Hazebroek ${ }^{15}$. \\ Miguel F. Herrera ${ }^{16}$ • Jacques M. Himpens ${ }^{17} \cdot$ Farah A. Hussain $^{18} \cdot$ Radwan Kassir $^{19} \cdot$ David Kerrigan $^{20}$. \\ Manish Khaitan ${ }^{21}$ • Lilian Kow ${ }^{22}$ • Jon Kristinsson ${ }^{23}$ • Marina Kurian ${ }^{24} \cdot$ Rami Edward Lutfi $^{25}$ • Rachel L. Moore ${ }^{26}$. \\ Patrick Noel ${ }^{27,28}$. Mahir M. Ozmen ${ }^{29}$. Jaime Ponce ${ }^{30}$. Gerhard Prager ${ }^{31}$. Sanjay Purkayastha ${ }^{32}$ • Juan Pujol Rafols ${ }^{33}$. \\ Almino C. Ramos ${ }^{34}$. Rui J. S. Ribeiro ${ }^{35}$ - Nasser Sakran ${ }^{36}$. Paulina Salminen ${ }^{37,38}$. Asim Shabbir ${ }^{39}$. Scott A. Shikora ${ }^{40}$. \\ Rishi Singhal ${ }^{41}$. Peter K. Small ${ }^{2,42}$. Craig J. Taylor ${ }^{43}$. Antonio J. Torres ${ }^{44} \cdot$ Carlos Vaz $^{45}$ - Yury Yashkov ${ }^{46}$. \\ Kamal Mahawar ${ }^{2,42}$
}

Received: 22 June 2020 / Revised: 20 July 2020 / Accepted: 28 July 2020 / Published online: 1 August 2020

(C) Springer Science+Business Media, LLC, part of Springer Nature 2020

\begin{abstract}
The purpose of this study was to achieve consensus amongst a global panel of expert bariatric surgeons on various aspects of resuming Bariatric and Metabolic Surgery (BMS) during the Coronavirus Disease-2019 (COVID-19) pandemic. A modified Delphi consensus-building protocol was used to build consensus amongst 44 globally recognised bariatric surgeons. The experts were asked to either agree or disagree with 111 statements they collectively proposed over two separate rounds. An agreement amongst $\geq 70.0 \%$ of experts was construed as consensus as per the predetermined methodology. We present here 38 of our key recommendations. This first global consensus statement on the resumption of BMS can provide a framework for multidisciplinary BMS teams planning to resume local services as well as guide future research in this area.
\end{abstract}

Keywords COVID-19 · Resuming elective surgery $\cdot$ Bariatric surgery · Obesity surgery

\section{Introduction}

Though many countries now appear to be past their Coronavirus Disease-2019 (COVID-19) peak, the world is still very much in the midst of a pandemic with tens of thousands of new cases being reported globally every day. Not only that the World Health Organisation has also warned that the Severe Acute Respiratory Syndrome Coronavirus 2 (SARS-CoV-2) virus, the causative agent of COVID-19, "may never go away" [1].

Multidisciplinary teams involved in the delivery of Bariatric and Metabolic Surgery (BMS) are trying to find ways to resume their services safely especially because there are expressed concerns that the COVID-19 pandemic might

Kamal Mahawar

kmahawar@gmail.com

Extended author information available on the last page of the article further aggravate the ongoing obesity pandemic [2]. Several guidelines have been published recently $[3,4]$ on how to safely resume BMS, but there is currently no global consensus on its various aspects.

Modified Delphi methodology for achieving consensus in areas of poor evidence and disagreements amongst professionals is now firmly rooted in clinical medicine including BMS [5-8]. They are recognised to be more robust and cheaper compared with consensus building in an open room setting. The purpose of this study was to achieve consensus amongst a global panel of expert bariatric surgeons on various aspects of resuming BMS during the COVID-19 era using a modified Delphi methodology.

\section{Methods}

We constituted a committee of 44 recognised opinion-makers in the field of BMS from 23 countries. These professionals are 
Table 1 Key consensus points in general and facility-specific considerations

\begin{tabular}{|c|c|c|}
\hline $\begin{array}{l}\text { Serial } \\
\text { no. }\end{array}$ & Statements & Final voting results \\
\hline 1. & A delayed elective BMS hinders the resolution of obesity and its co-morbidities. & $\begin{array}{l}\text { Agree } 100 \% \\
\quad(N=44)\end{array}$ \\
\hline 2. & The decision to resume BMS must be tailored to the local circumstances. & $\begin{array}{l}\text { Agree } 100 \% \\
\qquad(N=44)\end{array}$ \\
\hline 3. & Fellowship training requirements (caseload) should be altered during the pandemic. & Agree $75 \%(N=33)$ \\
\hline 4. & $\begin{array}{l}\text { All-cause and COVID-19-specific morbidity and mortality of BMS must be closely monitored in the initial phase } \\
\text { (first } 3 \text { months after resumption). }\end{array}$ & $\begin{array}{l}\text { Agree } 97.7 \% \\
\quad(N=43)\end{array}$ \\
\hline 5. & $\begin{array}{l}\text { The decision to resume BMS must be reviewed monthly by every institution that routinely performed BMS before the } \\
\text { pandemic. }\end{array}$ & $\begin{array}{l}\text { Agree } 97.7 \% \\
\quad(N=43)\end{array}$ \\
\hline 6. & $\begin{array}{l}\text { Hospital's provisions for Personal Protective Equipment (PPE) must be ensured, } \\
\text { and there should be clear policies on how and when to use which type of PPE. }\end{array}$ & $\begin{array}{l}\text { Agree } 100 \% \\
\qquad(N=44)\end{array}$ \\
\hline 7. & $\begin{array}{l}\text { If a separate hospital/clinic is not available, BMS should be carried out on a hospital wing or part, } \\
\text { which does not treat patients with Coronavirus Disease-19 (COVID-19). }\end{array}$ & $\begin{array}{l}\text { Agree } 100 \% \\
\qquad(N=44)\end{array}$ \\
\hline 8. & $\begin{array}{l}\text { Screening tests for SARS-CoV-2 should be performed in a designated facility where contact with other patients is } \\
\text { minimised. }\end{array}$ & $\begin{array}{l}\text { Agree } 100 \% \\
\qquad(N=44)\end{array}$ \\
\hline
\end{tabular}

recognised leaders in the field and include the current, the incumbent, and several past presidents of the International Federation for the Surgery of Obesity and Metabolic Disorders (IFSO); presidents or other office-bearers of many national obesity surgery societies; and many others recognised for academic excellence in the field. Sjaak Pouwels and Islam Omar were non-voting committee members.

The committee members collectively proposed a total of 111 statements to vote on in two separate rounds after discussions amongst themselves. The word "must" was used to suggest an essential requirement whereas "should" suggested a desirable requirement. The phrase "initial phase" indicated a period of 3 months upon resumption of BMS in that centre.
The members were asked to either agree or disagree with each statement. Following other published consensus papers [5-8], an agreement amongst $\geq 70.0 \%$ of experts was construed as consensus. Voting was conducted virtually on Typeform ${ }$, and no attempt was made to identify individual members' responses.

The first-round voting link was made live on 23 May 2020, and the second-round voting was concluded on 1 June 2020. The committee voted on 88 statements in the first round. In the second round, the committee voted on only those statements where there was an agreement/disagreement of $\geq 60.0 \%$ but not enough to reach the consensus threshold of $70.0 \%$. The committee did not vote again on statements with an

Table 2 Key consensus points in patient- and staff-specific testing and isolation considerations

\begin{tabular}{|c|c|c|}
\hline $\begin{array}{l}\text { Serial } \\
\text { no. }\end{array}$ & Statements & Final voting results \\
\hline 1. & Patients should undergo locally appropriate testing to screen for SARS-Cov-2 infection $24-72 \mathrm{~h}$ before BMS. & $\begin{array}{l}\text { Agree } 84.1 \% \\
\quad(N=37)\end{array}$ \\
\hline 2. & Patients must be screened for the symptoms of COVID-19, before arrival into the hospital. & $\begin{array}{l}\text { Agree } 93.2 \% \\
\quad(N=41)\end{array}$ \\
\hline 3. & Patients' hospitalisation time before BMS should be as short as possible. & $\begin{array}{c}\text { Agree } 100 \% \\
(N=44)\end{array}$ \\
\hline 4. & Patients must consent for the potential risk of acquiring SARS-CoV-2 infection during the hospital stay. & $\begin{array}{l}\text { Agree } 93.2 \% \\
\quad(N=41)\end{array}$ \\
\hline 5. & Patients must not have had any contact with a SARS-CoV-2 positive patient in the fortnight leading up to the operation. & $\begin{array}{l}\text { Agree } 95.5 \% \\
\quad(N=42)\end{array}$ \\
\hline 6. & BMS must be postponed if the preoperative COVID-19 antigen/ PCR test is positive. & $\begin{array}{l}\text { Agree } 100 \% \\
\quad(N=44)\end{array}$ \\
\hline 7. & $\begin{array}{l}\text { Healthcare professionals (involved in delivering BMS) with symptoms suggestive of COVID-19 must self-isolate for } \\
14 \text { days. }\end{array}$ & $\begin{array}{l}\text { Agree } 79.5 \% \\
(N=35)\end{array}$ \\
\hline 8. & $\begin{array}{l}\text { Healthcare professionals with symptoms suggestive of COVID-19 must be tested for SARS-Cov-2 infection before } \\
\text { resuming work. }\end{array}$ & $\begin{array}{l}\text { Agree } 97.7 \% \\
\quad(N=43)\end{array}$ \\
\hline
\end{tabular}


Table 3 Key consensus points in patient selection considerations

\begin{tabular}{|c|c|c|}
\hline $\begin{array}{l}\text { Serial } \\
\text { no. }\end{array}$ & Statements & $\begin{array}{l}\text { Final voting } \\
\text { results }\end{array}$ \\
\hline 1. & Qualifying criteria for BMS should be the same as before COVID. & $\begin{array}{l}\text { Agree } 88.6 \% \\
\quad(N=39)\end{array}$ \\
\hline 2. & The choice of the BMS procedure for an individual patient should not be influenced by the COVID-19 pandemic. & $\begin{array}{l}\text { Agree } 86.4 \% \\
\quad(N=38)\end{array}$ \\
\hline 3. & Patients' co-morbidities must be carefully optimised before BMS. & $\begin{array}{l}\text { Agree } 100 \% \\
\quad(N=44)\end{array}$ \\
\hline 4. & Revisional surgery for complication management must not be delayed. & $\begin{array}{l}\text { Agree } 93.2 \% \\
\quad(N=41)\end{array}$ \\
\hline 5. & $\begin{array}{l}\text { Patients with poorer cardio-pulmonary reserves (such as ischemic heart disease and COPD) should be avoided in the initial } \\
\text { phase (first } 3 \text { months after resumption). }\end{array}$ & $\begin{array}{l}\text { Agree } 72.7 \% \\
\quad(N=32)\end{array}$ \\
\hline 6. & Patients with $>2$ co-morbidities should be avoided in the initial phase (first 3 months after resumption). & $\begin{array}{l}\text { Agree } 86.4 \% \\
\quad(N=38)\end{array}$ \\
\hline 7. & Policy regarding routine preoperative endoscopy should be the same as before the COVID-19 pandemic. & $\begin{array}{l}\text { Agree } 77.3 \% \\
\quad(N=33)\end{array}$ \\
\hline
\end{tabular}

agreement/disagreement of $<60.0 \%$ in the first round, as previous consensus-building exercises have shown that these statements rarely achieve consensus even after the second round of voting $[5,6]$. The committee also introduced 23 new statements in the second round to further clarify some of the statements voted on in the first round.

\section{Results}

Forty-four globally recognised BMS experts from 23 countries voted on 111 statements on resuming bariatric practice in COVID-19 times. The committee achieved consensus on 72/ 88 statements voted on in the first round and 14/26 in the second round. Three statements were voted on again in the second round as per our methodology. None of these reached a consensus even after the second round of voting. The committee also added 23 new statements in the second round for further clarification of some of the aspects. In total, a consensus was achieved for 86 statements. Table 1 presents the results of voting on key general and facility-specific considerations. Amongst the important ones, there was a consensus of $97.7 \%$ on close monitoring of all-cause and COVID-19-specific morbidity and mortality of BMS in the initial phase after resumption; and with $100 \%$ consensus that if a separate hospital/ clinic was not available, BMS should be carried out on a hospital wing or part, which does not treat patients with COVID-19.

Table 2 presents the voting results on key patient and staff testing/isolation considerations. Amongst the important ones in this category, the committee agreed with $84.1 \%$ consensus that patients should undergo locally appropriate testing to

Table 4 Key consensus points in operative considerations

\begin{tabular}{|c|c|c|}
\hline $\begin{array}{l}\text { Serial } \\
\text { no. }\end{array}$ & Statements & Final voting results \\
\hline 1. & BMS must be performed laparoscopically or robotically. & $\begin{array}{l}\text { Agree } 86.4 \% \\
\quad(N=38)\end{array}$ \\
\hline 2. & Surgeons should allow more time for each patient whilst planning their operating theatre schedule. & $\begin{array}{l}\text { Agree } 90.9 \% \\
\quad(N=40)\end{array}$ \\
\hline 3. & There should be a minimum number of people present in the operating room. & $\begin{array}{l}\text { Agree } 95.5 \% \\
\quad(N=42)\end{array}$ \\
\hline 4. & $\begin{array}{l}\text { Surgical teams should wear the full PPE including an FFP3 or N-95 mask when operating on a COVID-positive } \\
\text { patient. }\end{array}$ & Agree $100 \%(N=44)$ \\
\hline 5. & Fully trained bariatric surgeons should perform the operations during the initial phase. & $\begin{array}{l}\text { Agree } 90.9 \% \\
\quad(N=40)\end{array}$ \\
\hline 6. & Surgeons should take care to avoid gas leakage during and especially at the end of the operation. & $\begin{array}{l}\text { Agree } 93.2 \% \\
\quad(N=41)\end{array}$ \\
\hline 7. & The surgeon should use a closed system to remove pneumoperitoneum at the end of the case & $\begin{array}{l}\text { Agree } 81.8 \% \\
\quad(N=36)\end{array}$ \\
\hline
\end{tabular}


Table 5 Key consensus points in postoperative considerations

\begin{tabular}{|c|c|c|}
\hline $\begin{array}{l}\text { Serial } \\
\text { no. }\end{array}$ & Statements & $\begin{array}{l}\text { Final voting } \\
\text { results }\end{array}$ \\
\hline 1. & Patients must follow an enhanced recovery after bariatric surgery protocol. & $\begin{array}{l}\text { Agree } 95.5 \% \\
\qquad(N=42)\end{array}$ \\
\hline 2. & If patients develop persistent cough or fever postoperatively, they should be tested for COVID-19. & $\begin{array}{l}\text { Agree } 100 \% \\
\quad(N=44)\end{array}$ \\
\hline 3. & Patients should self-isolate with family members at home for approximately 2 weeks after surgery. & $\begin{array}{l}\text { Agree } 81.8 \% \\
\quad(N=36)\end{array}$ \\
\hline 4. & Patients should undergo a telephonic follow-up within a week of discharge. & $\begin{array}{l}\text { Agree } 95.5 \% \\
\quad(N=42)\end{array}$ \\
\hline 5. & $\begin{array}{l}\text { Patients should be asked to seek urgent medical attention if they develop any unusual symptoms such as persistent cough, } \\
\text { fever, diarrhoea or vomiting. }\end{array}$ & $\begin{array}{l}\text { Agree } 100 \% \\
\qquad(N=44)\end{array}$ \\
\hline 6. & Patients should have easy and fast access to a medical team. & $\begin{array}{l}\text { Agree } 100 \% \\
\qquad(N=44)\end{array}$ \\
\hline 7. & Telemedicine should replace face-to-face consultation as much as possible. & $\begin{array}{l}\text { Agree } 90.9 \% \\
\quad(N=40)\end{array}$ \\
\hline
\end{tabular}

screen for SARS-CoV-2 infection 24-72 $\mathrm{h}$ before BMS; and with $97.7 \%$ consensus that healthcare professionals with symptoms suggestive of COVID-19 must be tested for SARS-CoV-2 infection before resuming work.

Table 3 presents the voting results on key patient selection considerations. There was a consensus of $88.6 \%$ that qualifying criteria for BMS should be the same as before COVID-19 pandemic; and $86.4 \%$ consensus that those with $>2$ comorbidities should be avoided in the initial phase.

Table 4 presents the voting results on key operative considerations. There was an $86.4 \%$ consensus that BMS must be performed laparoscopically or robotically and $100 \%$ consensus that surgical teams should wear the full PPE including an FFP3 or N-95 mask when operating on a COVID-positive patient.

Table 5 presents the voting results on key postoperative considerations. There was $81.8 \%$ consensus that patients should self-isolate with family members at home for approximately 2 weeks after surgery and $95.5 \%$ consensus that patients should undergo a telephonic follow-up within a week of discharge.

\section{Discussion}

This study represents the first multinational effort at achieving consensus amongst a group of globally recognised BMS experts on resuming bariatric surgery during the COVID-19 pandemic. The committee achieved a consensus on 86 statements they collectively proposed.

IFSO recently issued guidance advising postponement of all elective surgical and endoscopic BMS procedures during the pandemic [9]. However, it is not clear if and when this pandemic will end.
Furthermore, there are concerns that the COVID-19 pandemic may exacerbate the obesity crisis further [2] and some evidence that patients suffering from obesity may have worse outcomes with COVID-19. All these factors have led to a widespread recognition that BMS teams will have to find a way of resuming this surgery whilst the world is still in the middle of this pandemic. However, that task has proved difficult because of the scarce evidence base on the SARS-CoV-2 virus and COVID-19.

Expert advice is often the only tool for clinicians to base their decisions on in areas where robust evidence is lacking. At the same time, experts can also have differences amongst themselves. This makes a consensus amongst experts very useful for routine decision-making whilst the evidence catches up to inform practice. Consensus statements are recognised to be useful for identifying the most pragmatic course of action in areas of a poor evidence base. Modified Delphi consensusbuilding strategies are known to be more robust than traditional consensus-building approaches, which can often be hijacked by loud voices, and have been successfully used before in a multitude of clinical settings $[5,6]$

Rubino et al. [10] recently argued that patients with the greatest risk of morbidity and mortality from their disease should be prioritised in a resource-constrained environment in terms of availability of BMS. Significantly, and in contrast to Rubino et al. [10], our committee recommended avoiding patients with $>2$ co-morbidities in the initial phase with an $86.4 \%$ consensus. The committee also recommended $(72.7 \%)$ avoiding patients with poorer cardio-pulmonary in the initial phase. However, similar to Rubino et al., there was no agreement on any BMI cutoff for patient selection.

Several weaknesses of this paper need to be acknowledged. The choice of experts and the threshold of $70 \%$ for consensus can be considered arbitrary. A consensus agreement of a large 
number of experts is better quality evidence than the opinion of a single expert. But it is still an opinion that should ideally be confirmed in adequately designed studies. At the same time, one has to recognise that evidence on many of the aspects concerning the safe resumption of any elective surgery, let alone BMS, may take months - if not years - to develop.

\section{Conclusion}

In this first global attempt at consensus building on the resumption of BMS in COVID-19 times, 44 experts from 23 countries achieved consensus on a number of its aspects. These can provide a framework for BMS multidisciplinary teams working on local guidance as well as guide future research in this area.

Author Contributions KM conceived the idea for this exercise, moderated it and wrote some sections of the manuscript. IO helped with manuscript writing, drafting voting statements, analysis of results and submission process. SP helped with drafting voting statements, collecting and analysing votes and wrote the results and some other parts of the manuscript. All other authors helped with determining the methodology of the exercise, provided feedback at every stage, took part in the online voting, critically reviewed the draft of the manuscript and provided robust leadership. All authors have seen the final draft and approve of it.

\section{Compliance with Ethical Standards}

Conflict of Interest Author RB is a consultant for Johnson \& Johnson and a consultant for Verb.

Author AA received research grants from Medtronic outside the scope of this project. Author MF is a consultant for Bariatec Corporation.

Author CV is an advisory consultant to Intuitive, Medtronic, and Johnson \& Johnson. Author RM is a consultant for Medtronic and Allurion.

Author MK receives teaching honoraria from Medtronic. Author SS is the current Editor-In-Chief of Obesity Surgery.

The other authors declare that they have no conflict of interest.
Statement of Human and Animal Rights Not applicable.

Statement of Informed Consent Not applicable.

\section{References}

1. Available from: https://www.worldometers.info/coronavirus/. Accessed 15 June 2020.

2. Hussain A, Mahawar K, El-Hasani S. The impact of COVID-19 pandemic on obesity and bariatric surgery. Obes Surg. 2020:1-2.

3. COVID-19 Guidelines for metabolic and bariatric surgery patients [Available from: https://www.theossi.com/pdf/covid-19guidelines.pdf. Accessed 15 June 2020.

4. Daigle CR, Augustin T, Wilson R, et al. A structured approach for safely reintroducing bariatric surgery in a COVID-19 environment. Obes Surg. 2020:1-6.

5. Mahawar KK, Himpens J, Shikora SA, et al. The first consensus statement on one anastomosis/mini gastric bypass (OAGB/MGB) using a modified Delphi approach. Obes Surg. 2018;28(2):303-12.

6. Mahawar KK, Himpens JM, Shikora SA, et al. The first consensus statement on revisional bariatric surgery using a modified Delphi approach. Surg Endosc. 2020;34(4):1648-57.

7. Riddell MC, Gallen IW, Smart CE, et al. Exercise management in type 1 diabetes: a consensus statement. Lancet Diabetes Endocrinol. 2017;5(5):377-90.

8. Albury C, Strain WD, Brocq SL, et al. The importance of language in engagement between health-care professionals and people living with obesity: a joint consensus statement. Lancet Diabetes Endocrinol. 2020;8(5):447-55.

9. Yang W, Wang C, Shikora S, et al. Recommendations for metabolic and bariatric surgery during the COVID-19 pandemic from IFSO. Obes Surg. 2020;30(6):2071-3.

10. Rubino F, Cohen RV, Mingrone G, et al. Bariatric and metabolic surgery during and after the COVID-19 pandemic: DSS recommendations for management of surgical candidates and postoperative patients and prioritisation of access to surgery. Lancet Diabetes Endocrinol. 2020;8:640-8.

Publisher's Note Springer Nature remains neutral with regard to jurisdictional claims in published maps and institutional affiliations. 


\section{Affiliations}

\section{Sjaak Pouwels ${ }^{1}$ - Islam Omar ${ }^{2} \cdot$ Sandeep Aggarwal ${ }^{3}$. Ali Aminian ${ }^{4} \cdot$ Luigi Angrisani $^{5}$ - Jose María Balibrea ${ }^{6}$. Mohit Bhandari $^{7}$. L. Ulas Biter ${ }^{8}$. Robin P. Blackstone ${ }^{9}$. Miguel A. Carbajo ${ }^{10}$. Catalin A. Copaescu ${ }^{11}$. Jerome Dargent ${ }^{12}$. Mohamed Hayssam Elfawal ${ }^{13}$ • Mathias A. Fobi ${ }^{7}$. Jan-Willem Greve ${ }^{14}$. Eric J. Hazebroek ${ }^{15}$. Miguel F. Herrera ${ }^{16}$ • Jacques M. Himpens ${ }^{17}$ • Farah A. Hussain ${ }^{18} \cdot$ Radwan Kassir $^{19}$. David Kerrigan $^{20}$. Manish Khaitan ${ }^{21}$ • Lilian Kow ${ }^{22}$ • Jon Kristinsson ${ }^{23}$ • Marina Kurian ${ }^{24}$ - Rami Edward Lutfi ${ }^{25}$ - Rachel L. Moore ${ }^{26}$. Patrick Noel ${ }^{27,28}$. Mahir M. Ozmen ${ }^{29}$. Jaime Ponce ${ }^{30}$. Gerhard Prager ${ }^{31}$ - Sanjay Purkayastha ${ }^{32}$ • Juan Pujol Rafols ${ }^{33}$. Almino C. Ramos ${ }^{34}$ • Rui J. S. Ribeiro ${ }^{35}$ - Nasser Sakran ${ }^{36}$. Paulina Salminen ${ }^{37,38}$. Asim Shabbir ${ }^{39}$. Scott A. Shikora ${ }^{40}$. Rishi Singhal ${ }^{41}$ • Peter K. Small ${ }^{2,42}$ • Craig J. Taylor ${ }^{43}$. Antonio J. Torres ${ }^{44} \cdot$ Carlos Vaz $^{45}$ • Yury Yashkov ${ }^{46}$. Kamal Mahawar ${ }^{2,42}$ (1)}

1 Department of Intensive Care Medicine, Elisabeth Tweesteden Hospital, Tilburg, The Netherlands

2 Bariatric Unit, South Tyneside and Sunderland NHS Trust, Sunderland SR4 7TP, UK

3 All India Institute of Medical Sciences (AIIMS), New Delhi, India

4 Cleveland Clinic, Cleveland, OH, USA

5 Public Health Department - Federico II School of Medicine, University of Naples, Naples, Italy

6 Hospital Clínic de Barcelona, Barcelona, Spain

7 Mohak Bariatric and Robotic Surgery Center Indore, Indore, India

8 Franciscus Gasthuis Rotterdam, Rotterdam, The Netherlands

9 University of Arizona, Tucson, AZ, USA

10 Center of Excellence for the Study and Treatment of the Obesity and Diabetes, Valladolid, Spain

11 Ponderas Academic Hospital, Bucharest, Romania

12 Polyclinique Lyon Nord, Rillieux-la-Pape, France

13 Makassed General Hospital, Beirut, Lebanon

14 Zuyerland Medical Center, University of Maastricht, Maastricht, The Netherlands

15 Rijnstate Hospital Arnhem, Arnhem, Netherlands

16 Instituto Nacional de Ciencias Médicas y Nutrición Salvador Zubirán, Ciudad de México, Mexico

17 CHIREC Delta Hospital, Auderghem, Belgium

18 Oregon Health \& Science University, Portland, OR, USA

19 Department of Bariatric Surgery, CHU Félix Guyon, Saint Denis, La Réunion, France

20 Phoenix Health, Chester, UK

21 KD Hospital, Ahmedabad, India

22 Flinders University, Adelaide, South Australia, Australia

23 Oslo University Hospital, Oslo, Norway
24 New York University School of Medicine, New York, NY, USA

25 University of Illinois, Chicago, IL, USA

26 Private Practice, New York, NY, USA

27 Bouchard Private Hospital, Elsan, Marseille, France

28 Mediclinic Parkview, Dubai, United Arab Emirates

29 Istinye University, Istanbul, Turkey

30 CHI Memorial Hospital, Chattanooga, TN, USA

31 Medical University of Vienna, Wien, Austria

32 Imperial College (On Behalf of the PanSurg Collaborative), London, UK

33 Clínica Mi Tres Torres, Barcelona, Spain

34 Gastro Obeso Center, Sao Paulo, Brazil

35 CLISA-Lusiadas, Amadora, Portugal

36 Emek Medical Center, Afula, Israel

37 Turku University Hospital, Turku, Finland

38 Satasairaala Central Hospital, Pori, Finland

39 National University Hospital, Singapore, Singapore

40 Brigham and Women's Hospital, Harvard Medical School, Boston, MA, USA

41 Birmingham Heartlands Hospital, University Hospital Birmingham NHS Foundation Trust, Birmingham, UK

42 Faculty of Health Sciences and Wellbeing, University of Sunderland, Sunderland, UK

43 Concord Repatriation General Hospital, Sydney, Australia

44 Hospital Clinico San Carlos, Universidad Complutense Madrid, IdISSC, Madrid, Spain

45 Hospital CUF Tejo, Lisbon, Portugal

46 CELT-clinic, Moscow, Russia 